\title{
EL NECESARIO REFUERZO DE LA COOPERACIÓN BILATERAL EN LA LUCHA CONTRA EL TERRORISMO YIHADISTA
}

\author{
Patricia Rodríguez ${ }^{1}$ \\ UNISCI / Universidad Complutense de Madrid (UCM)
}

\begin{abstract}
Resumen:
Los atentados del 11 de marzo de 2004 organizados por una célula islamista asentada en España dejaron patente que la amenaza yihadista es real. Este artículo analiza la evolución de la política exterior española en relación con el terrorismo islamista en la primera década del siglo XXI. Dos presidentes y dos políticas diferenciadas: la primera, con José María Aznar, de vocación atlantista y estrecha relación con Estados Unidos; la segunda, con José Luis Rodríguez Zapatero, marcada por el pronunciado desencuentro con Washington y un refuerzo de sus relaciones con los países de la Unión Europea y el Magreb. La dificultad de alcanzar acuerdos en organismos internacionales por la ausencia de una definición de terrorismo consensuada a nivel internacional y por la presencia de algunos Estados musulmanes que no separan los movimientos independentistas de los grupos terroristas hace del refuerzo de las relaciones bilaterales un arma clave contra la amenaza del terrorismo islamista por su capacidad para materializarse en actos concretos.
\end{abstract}

Palabras clave: Política exterior, terrorismo islamista, España, Estados Unidos, Magreb.

Title in English: "The Need to Reinforce Bilateral Cooperation in the Fight against Jihadi Terrorism”.

Abstract:

The terrorist attacks of March 11 in Madrid, organized by an Islamist cell based in Spain, made it clear that the Jihadist threat is real. This article analyzes the evolution of Spanish foreign policy in relation to Islamist terrorism in the first decade of the 21 st century. Two presidents and two different policies: the first one, with José María Aznar, was characterized by its vocation Atlanticist and a close relationship with the United States. The second one, with Jose Luis Rodriguez Zapatero, was marked by the sharp disagreement with Washington and closer relations with the countries of European Union and the Maghreb. The difficulty of reaching agreement on international organizations because of the absence of an agreed definition of terrorism at an international level and because of the presence of some Muslim states that do not separate the independence movements of terrorist groups makes the reinforcement of bilateral relations a key weapon against the threat of Islamist terrorism for its ability to materialize into specific actions.

Keywords: Foreign Policy, Islamist terrorism, Spain, United States, Maghreb.

Copyright (C) UNISCI, 2011.

Las opiniones expresadas en estos artículos son propias de sus autores, y no reflejan necesariamente la opinión de UNISCI. The views expressed in these articles are those of the authors, and do not necessarily reflect the views of UNISCI.

\footnotetext{
${ }^{1}$ Patricia Rodríguez Blanco es investigadora UNISCI, especialista en movimientos islamistas. Email: rodriguez.blanco@gmail.com. http://dx.doi.org/10.5209/rev_UNIS.2011.v27.38152
} 


\section{Introducción}

La política exterior española en relación con el terrorismo islamista ha estado marcada en la primera década del siglo XXI por los atentados de Nueva York del 11 de septiembre de 2001 y por los atentados de Madrid del 11 de marzo de 2004, en los que perdieron la vida 191 personas y más de 1.500 resultaron heridas. Los ataques contra los trenes de Atocha, ejecutados por una célula islamista asentada en España, pusieron de manifiesto que los riesgos y amenazas del terrorismo internacional relacionado con la yihad neosalafista son de origen externo e interno. Proceden tanto de grupos y organizaciones vinculadas con redes, fundamentalmente norteafricanas, o por inmigrantes de origen magrebí -aunque aumenta la presencia de los de origen asiático-que viven en suelo español. ${ }^{2}$

En la actualidad, España y sus ciudadanos son objetivo de Al Qaeda, tanto dentro como fuera del territorio español. La organización terrorista, que hasta su muerte a manos de las tropas estadounidenses ${ }^{3}$ dirigía Osama Bin Laden, interpreta la presencia de las tropas españolas en países musulmanes como una provocación, como un motivo para convertirla en blanco de sus agresiones, tal y como han manifestado públicamente a través de vídeos enviados a la cadena de televisión catarí Al Yazira o colgados en Internet.

Pero Al Qaeda también recurre a viejos motivos históricos en sus amenazas. La expulsión de los musulmanes de la península Ibérica en 1492 o la presentación de España como parte del imaginario del islam, que reivindica la recuperación del Al Andalus musulmán desaparecido hace más de cinco siglos, ha formado parte de la dialéctica desafiante de los terroristas durante la última década.

Las amenazas son conocidas. La primera de ellas tuvo lugar el 7 de octubre de 2001, pocos días después de los atentados del 11 de septiembre, a través de un vídeo en el que Al Qaeda llamaba a la guerra santa, y donde el entonces número dos de la organización terrorista, Ayman Zawahiri, comparaba la expulsión de los musulmanes de España a finales del siglo XV con la situación de los palestinos en territorios ocupados.

El 11de de marzo de 2004 se produjeron los atentados contra los trenes en Madrid. El Partido Popular, que realizó una pésima gestión de este ataque terrorista, perdió las elecciones generales que se celebraron tres días más tarde. Pero ni siquiera la victoria de su opositor, el socialista José Luis Rodríguez Zapatero, fue suficiente para que la organización terrorista dejara de considerar a España colaboradora de "los criminales de Bush y sus aliados" de que la retirada de las tropas de Irak fuera uno de los ejes principales de la campaña electoral de Zapatero ${ }^{5}$, y de que la victoria de éste supusiera, consecuentemente, la derrota del partido de su antecesor, José María Aznar, el presidente que autorizó, pese a la contestación de la opinión pública española, el apoyo a la invasión de Irak y la presencia posterior del ejército de España en Irak.

Así, el 2 de abril de 2004, coincidiendo con el hallazgo de un artefacto en la línea ferroviaria del AVE, con el mismo explosivo utilizado en el 11-M, se hizo público el envío de una carta de las Brigadas de Abu Hafs a la Embajada española en Egipto, en la que los terroristas señalaban que "las embajadas e intereses españoles" en el norte de África eran su

\footnotetext{
${ }^{2}$ Ceberio Belaza, M.: “Al Qaeda no tiene células operativas en España”, El País, 11 de marzo de 2011.

3 “Osama Bin Laden Dead", en el Blog de la Casa Blanca, en http://www.whitehouse.gov/blog/2011/05/02/osama-bin-laden-dead.

${ }^{4}$ Yoldi, J.: "Identificada la voz del vídeo que se atribuyó los atentados", El País, 17 de marzo de 2004.

${ }^{5}$ Programa electoral del PSOE a las elecciones generales de 2004, p. 13.
} 
objetivo si España no retiraba en "cuatro semanas" sus tropas de Irak y Afganistán, donde llegaron a finales de enero de 2002 bajo mandato de la OTAN. ${ }^{6} \mathrm{Y}$ dos día más tarde, Ansar Al Qaeda en Europa amenazó, en una nota enviada al diario $A B C$ con convertir España "en un infierno" si no cesaba el apoyo a Estados Unidos. Horas antes, siete terroristas se suicidaban en un piso de Leganés. ${ }^{7}$

El manifiesto rechazo del Gobierno socialista "al apoyo incondicional" que España había prestado bajo el mandato de Aznar a la "ilegal intervención militar de Estados Unidos y del Reino Unido en Irak" ", tampoco contentó a los de Osama Bin Laden. Zapatero anunció el 18 de abril de 2004, un día después de haber sido investido presidente, la retirada del contingente español de Irak "en el menor tiempo posible". El anunció no calmó a la organización terrorista, aunque sí interrumpió sus ataques verbales por un tiempo.

No fue hasta el 12 de marzo de 2007 cuando Al Qaeda volvió a dirigirse a España y advirtió en un vídeo al Gobierno de Zapatero de que la presencia de soldados españoles en Afganistán "pone en peligro otra vez a su país". ${ }^{10}$ Meses más tarde, el 20 de septiembre de aquel mismo año, en un vídeo difundido a través de varias webs islamistas, el lugar teniente de Bin Laden, Ayman Zawahiri, pidió "limpiar el Magreb islámico de los hijos de Francia y España". ${ }^{11}$

La amenaza de Al Qaeda se acercaba así a las fronteras españolas. Y se hizo real el 29 de noviembre de 2009, cuando un grupo de hombres armados que pertenecían a AQMI (Al Qaeda en el Magreb Islámico), secuestró en Mauritania a tres cooperantes españoles de la ONG catalana Barcelona Acció Solidària. El 8 de diciembre de ese mismo año los terroristas reivindicaron el secuestro a través de un comunicado que emitió la cadena Al Yazira. ${ }^{12}$

Al Qaeda no ha hecho nunca diferencias entre el Gobierno de José María Aznar (19972004) y el de José Luis Rodríguez Zapatero (2004-2011). Tanto la participación de España en la posguerra de Irak, como la presencia de las tropas españolas en Afganistán, con mandato de Naciones Unidas, convierten España en blanco de los terroristas islamistas. ¿Cabe plantearse si España debe ceder ante estas amenazas para escapar de la violencia asesina de Al Qaeda? Todo lo contrario, la presencia española en misiones internacionales, como la de Afganistán, y siempre dentro de la legalidad internacional, no sólo refuerzan el papel de España en la esfera internacional sino que forma parte de la estrategia antiterrorista, ${ }^{13}$ en la medida en que impide, como es en el caso del país asiático, que su territorio sea utilizado por Al Qaeda como base para adiestrar a sus miembros y para organizar e instigar atentados terroristas, sea contra España y sus intereses como contra los de otros países aliados.

\footnotetext{
${ }^{6}$ González, Miguel: “Trillo anuncia que España enviará tropas a Afganistán bajo mando de la OTAN”, El País, 16 de noviembre de 2001.

${ }^{7}$ Basco, Sebastián: “Al Qaida advierte en un comunicado a ABC de que la tregua ha terminado y habrá más matanzas", $A B C$, 5 de abril de 2004.

${ }^{8}$ Programa electoral del PSOE a las elecciones generales de 2004, p. 13.

${ }^{9}$ R. Aizpeolea, Luis: "Zapatero anuncia la retirada de las tropas de Irak en "el menor tiempo posible", El País, 19 abril de 2004.

10 “Al Qaeda amenaza a España por el envío de tropas a Afganistán”, El País, 13 de marzo de 2007.

${ }^{11}$ Cembrero, Ignacio: “"Eliminad a España y Francia del Magreb", El País, 21 de septiembre de 2007.

12 "Al-Qaeda group claims kidnappings", Al Yazira, 8 de diciembre de 2008, en http://english.aljazeera.net/news/africa/2009/12/20091287345403295.html.

${ }^{13}$ Estrategia Española de Seguridad 2011, documento facilitado por el servicio de prensa del Ministerio del Interior de España.
} 


\section{Estrategia antiterrorista: una aproximación desde la multilateralidad}

Los atentados del 11 de marzo dejaron ya claro que las supuestas amenazas del terrorismo yihadista contra España trascienden el plano de las advertencias. El carácter global del terrorismo yihadista obliga a combatirlo desde una perspectiva también global. Los Estados no sólo deben hacer frente a las células instaladas dentro de sus fronteras sino a todos los actores que forman parte de la red de Al Qaeda, sus extensiones territoriales o los grupos que les son afines por su capacidad, tanto para atentar como para instigar atentados contra intereses occidentales. $^{14}$

Sin embargo, abordar el terrorismo en foros internacionales es de una enorme complejidad, fundamentalmente por la falta de acuerdo entre los expertos a la hora de formular una definición del fenómeno.

El Consejo de Seguridad de Naciones Unidas hizo un intento de aproximación en su resolución 1566, en la que condena "en los términos más enérgicos todos los actos de terrorismo, cualquiera que sea su motivación y cuando quiera y por quien quiera que sean cometidos". La misma resolución desliza un intento de definición cuando recuerda que "no admiten justificación en circunstancia alguna por consideraciones de índole política, filosófica, ideológica, racial, étnica, religiosa u otra similar" los actos criminales, inclusive contra civiles, "cometidos con la intención de causar la muerte o lesiones corporales graves o de tomar rehenes con el propósito de provocar un estado de terror en la población en general, en un grupo de personas o en determinada persona, intimidar a una población u obligar a un gobierno o a una organización internacional a realizar un acto, o a abstenerse de realizarlo". ${ }^{15}$

A pesar de las dificultades y de su cuestionado resultado, España ha formado parte de distintos procesos orientados a fortalecer la colaboración internacional en materia de seguridad y de lucha antiterrorista. En el seno de Naciones Unidas, España ha desempeñado un papel activo en el Comité contra el Terrorismo del Consejo de Seguridad, al conseguir colocar como director ejecutivo, en mayo de 2004, al embajador español Javier Rupérez. El Comité, que hoy en día preside Mike Smith, supervisa la aplicación de la resolución 1373 que contempla, entre sus objetivos principales, tipificar como delito la financiación del terrorismo, congelar los fondos de quienes participen en actos terroristas, denegar cualquier tipo de apoyo a grupos terroristas e intercambiar información y colaborar con otros Gobiernos en materia antiterrorista.

Dentro de los acuerdos que ambicionan un alcance global, España pertenece al Grupo de Acción contra el Terrorismo del G- $8,{ }^{16}$ creado en 2003 por las ocho grandes potencias de la comunidad internacional -EE UU, Alemania, Francia, Reino Unido, Italia, Canadá, Japón y Rusia- para actuar como autoridad supranacional, en materia antiterrorista, entre los países que se adhieran. El organismo se marcó como objetivos básicos impedir "la adquisición de

\footnotetext{
${ }^{14}$ Reinares, Fernando: "El terrorismo global, un fenómeno polimorfo", Real Instituto Elcano, ARI, n 84, 23 de julio de 2008, en

http://www.realinstitutoelcano.org/wps/portal/rielcano/contenido?WCM_GLOBAL_CONTEXT=/elcano/elcano es/zonas_es/terrorismo+internacional/ari84-2008.

${ }^{15}$ Resolución 1566 (2004) del Consejo de Seguridad de Naciones Unidas, en http://ftp.cnbs.gov.hn/uif_pdf/48_Resolucion_1566_Consejo_Seguridad.pdf.

${ }_{16}$ Discurso del ex-ministro español de Asuntos Exteriores Miguel Ángel Moratinos en el balance de Política Exterior 2006-2007, el 19 de junio de 2007.
} 
armas de destrucción masiva por parte de terroristas y otros criminales" y fortalecer "la voluntad política internacional para combatir el terrorismo". ${ }^{17}$

A nivel europeo, España es miembro de la OSCE, organismo que presidió en 2007, y que persigue, entre sus fines prioritarios, contribuir a fortalecer la seguridad y los valores democráticos del continente, prestando especial atención a la lucha contra el terrorismo a través de la cooperación y el respeto a las reglas democráticas. Sin embargo, la decreciente capacidad de acción de la OSCE obliga a cuestionarse si es uno de los escenarios desde los que poder hacer frente al terrorismo yihadista.

España ha intentado tener un papel más influyente en la esfera internacional erigiéndose en impulsora de organismos con vocación de intervenir en los asuntos globales, como el Proceso de Barcelona, transformado posteriormente en una fracasada Unión por el Mediterráneo, que no termina de arrancar. Probablemente, su mayor logro en la lucha antiterrorista fue la firma en noviembre de 2005 del Código de Conducta Euro-mediterráneo sobre Contraterrorismo. Los países firmantes se mostraron unidos "en la lucha contra el terrorismo" y reiteraron "su total condena al terrorismo en todas sus formas y manifestaciones" y su determinación a "erradicar y combatir a sus patrocinadores". ${ }^{18}$ Sin embargo, el texto adolece de una definición de terrorismo, porque no todos los países lo entienden de la misma manera, e incluso entre algunos gobernantes árabes hay simpatía y hasta patrocino explícito de algunas organizaciones que la Unión Europea ha incluido en el listado de grupos terroristas. ${ }^{19}$

Sin embargo, es la Alianza de Civilizaciones la que mejor recoge la esencia del programa electoral de Zapatero en los comicios generales de 2004 en sus relaciones exteriores, donde apostó por el paraguas de la legalidad internacional para las operaciones militares fuera de España. ${ }^{20}$ La Alianza de Civilizaciones fue una apuesta personal del presidente español, que copatrocinó junto con el primer ministro turco, Recep Tayip Erdogan, y que presentó en la Asamblea General de la ONU en septiembre de 2004, apenas seis meses después de haber sido elegido como jefe del Ejecutivo. "Uno de los mayores retos que afrontamos actualmente es revertir la actual interacción negativa y desconexión entre Occidente y el mundo islámico, ruptura que está favoreciendo la involución hacia políticas basadas en la identidad en las que florece el extremismo", escribieron Zapatero y Erdogan en un artículo conjunto publicado en el diario EL PAÍS el 11 de noviembre de 2006. Según los copatrocinadores, la Alianza de Civilizaciones responde "a un amplio consenso entre naciones, culturas y civilizaciones de que todas las sociedades son interdependientes y su desarrollo, seguridad y prosperidad van unidos". Aunque el pasado 14 de febrero Zapatero y el Alto Representante de Naciones Unidas para la Alianza de Civilizaciones, Jorge Sampaio, subrayaron la vigencia de la alianza, queda por analizar sus logros reales conseguidos. La Alianza de Civilizaciones carece, quizá, de suficiente entidad para contribuir a semejante fin. $^{21}$

\footnotetext{
17 "Terrorism", G8 Information Centre, en www.g8.utoronto.ca/evaluations/2005compliance final/2005-16-g8-f-comp terrorism.pdf.

18 "Código de Conducta Euromediterráneo sobre Contraterrorismo", Cumbre Euromediterránea 2005, en http://www.euromedbarcelona.org/NR/rdonlyres/3F64E0D6-A00F-45E5-88C20CAA7D03D187/0/EUROMEDCodeConductFINAL28NOV.pdf.

${ }^{19}$ Reinares, Fernando: "Mediterráneo y terrorismo internacional: ¿un nuevo marco para la cooperación?”, Real Instituto Elcano, ARI, no 149,12 de diciembre de 2005.

${ }^{20}$ Programa electoral del PSOE a las elecciones generales de 2004, p. 14.

${ }^{21}$ Reinares, Fernando: “AAlianza de civilizaciones frente al terrorismo?”, El País, 14 de diciembre de 2006.
} 
En el seno de la Unión Europea, España trató de imprimir su huella en la lucha antiterrorista durante sus dos presidencias de la primera década del siglo XXI. En la primera, entre enero y junio de 2002, con José María Aznar como presidente, España se marcó la lucha contra el terrorismo, especialmente contra la financiación, como una de sus principales prioridades. Además situó entre sus objetivos el impulso de la colaboración entre jueces y de la cooperación entre las Fuerzas de Policía europeas, así como el fortalecimiento de la cooperación en materia policial y judicial con Estados Unidos. ${ }^{22}$

En su segundo mandato, durante el primer semestre de 2010, y ya con José Luis Rodríguez Zapatero al frente del Ejecutivo, uno de los mayores logros de la presidencia española en materia antiterrorista fue la firma de un acuerdo de seguridad aérea con Estados Unidos, la declaración de Toledo, como reacción al ataque contra el avión norteamericano con destino a Detroit, el 25 de diciembre de 2009. Los países firmantes se comprometieron a identificar materiales ilegales, fortalecer la seguridad a bordo e intercambiar información en casos de emergencia. Esta declaración ha servido como base para acuerdos bilaterales similares entre EE UU y los países miembros. Además, se aprobó una resolución para crear equipos multinacionales con terceros países para operaciones de contraterrorismo a escala internacional y la Unión Europea se comprometió a ayudar a la Administración estadounidense de Barack Obama a abandonar el concepto de "guerra contra el terrorismo". ${ }^{23}$

En cuanto a sus propias iniciativas como Estado soberano, España aprobó el Plan África el 19 de mayo de 2006 con el fin de apoyar los procesos de consolidación de la democracia y la construcción de la paz y la seguridad en África, contribuir a la lucha contra la pobreza, promover las relaciones comerciales y de inversión con España y del desarrollo económico africano, consolidar la asociación en materia migratoria, reforzar la relación de la Unión Europea con África y consolidar la presencia política e institucional española en el continente. ${ }^{24}$ El plan, previsto en un primer momento para una duración de tres años, ha sido extendido, por el momento, hasta 2012. Por primera vez un instrumento de cooperación para una región determinada incluyó acciones específicas en el ámbito de la lucha contra el terrorismo en la medida en que reconoció que el peligro derivado de la difusión de ideologías extremistas y la posibilidad de implantación de redes de apoyo a terroristas en algunas regiones de África planteaban un reto para la seguridad de España. ${ }^{25}$

Si bien España no puede dejar de participar en foros, organismos y procesos internacionales contra el terrorismo, por su responsabilidad y su compromiso con la defensa de los derechos humanos, la expansión de la democracia y el cumplimiento de la legalidad internacional, su eficacia es discutible y dudosa porque los acuerdos no traspasan la esfera de los compromisos, carecen de carácter vinculante y en ellos participan, en muchas ocasiones, países cuyos gobiernos simpatizan con ciertos grupos que la Unión Europea y Estados Unidos consideran organizaciones terroristas. Además, aunque se han dado pasos importantes en un acercamiento sobre lo que constituye la definición del terrorismo, todavía queda el importante escollo de la separación que se tiende a realizar en el mundo árabe entre luchadores de movimientos de liberación y movimientos terroristas. Mientras que los países no resuelvan

\footnotetext{
22 “Comunicado del Ministerio del Interior", 17 de enero de 2002.

${ }^{23}$ Declaración Conjunta de Toledo, en

http://www.mir.es/DGRIS/Documentos/Documentos_ambito_europeo/Declaracion_Toledo_enero_2010.

24 "Plan África 2009-2012", Ministerio de Asuntos Exteriores, en http://www.maec.es/es/Home/Documents/PLAN\%20AFRICA\%202009-2012_web.pdf.

${ }^{25}$ Barrenechea, Luisa: "El Plan África dentro de las iniciativas de la política exterior de España en la lucha contra el terrorismo", FRIDE, enero de 2007, en http://www.fride.org/publicacion/178/otras-publicaciones.
} 
este obstáculo, las aproximaciones a la lucha antiterrorista desde una perspectiva multilateral quedarán en papel mojado.

\section{Las relaciones bilaterales: el paso a la acción}

Junto al fortalecimiento de las Fuerzas y Cuerpos de Seguridad del Estado, con el desarrollo de planes operativos concretos para la lucha antiterrorista y, en particular, la amenaza yihadista, el refuerzo de las relaciones exteriores se convierte en una de las líneas estratégicas de acción esenciales, ${ }^{26}$ tanto en el plano multilateral como en el bilateral, aunque es éste último el que se ha demostrado más efectivo o el que se ha materializado, en un mayor número de ocasiones, en acciones concretas en la lucha antiterrorista.

Son especialmente las relaciones bilaterales con los países del norte de África, y fundamentalmente con Marruecos y Argelia, las que interesan a España en este aspecto. Así lo demuestran la existencia de Estados fallidos en el África subsahariana, relativamente próximos a las costas españolas, que favorece el desarrollo de organizaciones y células terroristas, y su proximidad con el Magreb, caldo de cultivo para el terrorismo islamista al amparo de Al Qaeda -la aparición de AQMI (Al Qaeda en el Magreb Islámico) es la mejor muestra de ello-. ${ }^{27}$

Sin embargo, el antropólogo británico Jeremy Keenan vincula la aparición de AQMI a la acción de los servicios secretos argelinos en colaboración con Estados Unidos y no a la expansión de Al Qaeda. ${ }^{28}$ Según Keenan, la política de guerra contra el terror desarrollada por la Administración de George W. Bush tras los atentados del 11-S necesitaba demostrar que el brazo de Osama Bin Laden se aproximaba a la frontera sur de Europa para militarizar África. Pero apenas había terrorismo en el continente, excluyendo los atentados en los hoteles de Mombasa (Kenia) en 1998, y algunos incidentes en Egipto, en el norte de África y en la costa argelina. Para extender la idea de que el terrorismo islámico operaba en la costa sur del Mediterráneo, no quedaba otra alternativa que fabricarlo. Y el encargado fue el Departamento de Información y Seguridad de Argelia (DRS, en su sigla en francés), que propició el secuestro de turistas europeos que viajaban por el Sáhara argelino.

No obstante, la amenaza de AQMI existe y España estima de capital trascendencia para la seguridad que en esta región impere el bienestar y la estabilidad, tal y como señala el Ministerio de Asuntos Exteriores, que subraya la importancia de la cooperación entre las autoridades españolas y magrebíes en el ámbito policial, para identificar y prevenir riesgos, y en el judicial, para evitar la impunidad de quienes delinquen. ${ }^{29}$

\footnotetext{
${ }^{26}$ Estrategia Española de Seguridad 2011, p. 47.

${ }^{27}$ Ibid., p. 48.

${ }^{28}$ Entrevista de Amy Goodman a Jeremy Keenan, 6 de agosto de 2009, en http://www.democracynow.org/2009/8/6/keenan.

29 "Política Exterior de España en África del Norte", Ministerio de Asuntos Exteriores de España, en http://www.maec.es/es/menuppal/paises/MOrienteyMagreb/Paginas/OrienteMedioyMagreb.aspx.
} 


\subsection{Marruecos}

La relación que España mantiene con Marruecos es de carácter privilegiado. Es el primer país del Magreb con el que firmó un Tratado de Amistad, Buena Vecindad y Cooperación (1991). Sin embargo, no ha estado exenta de enfrentamientos, especialmente durante los dos Gobiernos de José María Aznar (1997-2001 y 2001-2004), que priorizó las relaciones trasatlánticas por encima de las europeas, las iberoamericanas y, por supuesto, las de los países del norte de África. ${ }^{30}$

La crisis diplomática bilateral desencadenada durante la segunda legislatura de José María Aznar (2001-2004) no perturbó la colaboración en la lucha antiterrorista. Los servicios secretos españoles y marroquíes ya reforzaron su cooperación en este asunto tras los atentados del 11 de septiembre, según fuentes policiales de ambos países. ${ }^{31}$

Sin embargo, el empeoramiento de las relaciones hispano-marroquíes dejó su huella. El enfrentamiento ya había comenzado meses antes de los ataques contra las Torres Gemelas principalmente por los desencuentros en los acuerdos de pesca con la Unión Europea -Rabat se negaba a renovarlos para presionar en sus intereses sobre el Sáhara-, aunque la situación empeoró apenas un mes y medio después, el 27 de octubre de 2001, cuando el Reino de Marruecos llamó a consultas a su embajador. Alcanzó, no obstante, su mayor intensidad con la crisis de Perejil. El 11 de julio de 2002 un grupo de gendarmes marroquíes se instalaron en el islote, que los dos países reivindican, España llamó a consultas a su embajador y envió una unidad de operaciones especiales formada por 28 soldados, que tomaron la isla, expulsaron a los agentes marroquíes e izaron la bandera española. No sería hasta el 30 de enero de 2002 cuando los ministros de Asuntos Exteriores de los dos países decidieron la vuelta de los respectivos embajadores.

Aunque la crisis diplomática entre España y Marruecos no bloqueó la cooperación en la lucha antiterrorista, sí afectó al intercambio de información en materia de narcotráfico e inmigración ilegal. O al menos así lo reconoció el ministro del Interior marroquí, Mustapha Sahel: "Cuando llegué al frente de este departamento [en noviembre de 2002], pude constatar la carencia de reacción, por ambos lados, en algunos asuntos, como la emigración clandestina o la lucha contra el tráfico de droga". ${ }^{32}$

También lo constatan los servicios secretos españoles, que se percataron, tras los atentados del 11 de marzo, de que existe una vinculación estrecha entre el terrorismo islamista y los delitos comunes. "El 11-M nos rompió los esquemas. Antes no vinculábamos jamás a un yihadista con un delincuente común, con un traficante de drogas o con redes de inmigración ilegal porque su propia doctrina condenaba estas acciones", afirma en una entrevista en EL PAÍS el 11 de marzo de 2011 uno de los mayores expertos en terrorismo islamista en España, analista de la Comisaría General de Información de la Policía Nacional, que participó en la investigación y que prefiere no desvelar su identidad por razones de seguridad. ${ }^{33}$ El politólogo Jean Pierre Filiu subraya esta dimensión de los terroristas islamistas, vinculados a otro tipo de delitos: "Los líderes de Al Qaeda recurren al islam para justificar sus acciones, pero sus objetivos son eminentemente políticos, en la medida en que buscan destruir y transformar

\footnotetext{
${ }^{30}$ Feliú, Laura: “España y El Magreb durante el segundo mandato del Partido Popular. Un período excepcional”, FRIDE, mayo de 2005.

${ }^{31}$ Ignacio, Cembrero (2006): "El caldo de cultivo terrorista", en Vecinos alejados: los secretos de la crisis entre España y Marruecos, Barcelona, Galaxia Gutemberg, pp. 142-158.

${ }^{32}$ Ibid., Ídem.

${ }^{33}$ Ceberio Belaza, Mónica: “Al Qaeda no tiene células operativas en España”, El País, 11 de marzo de 2011.
} 
radicalmente las estructuras sociales, políticas, económicas y administrativas de los escenarios en los que actúan". ${ }^{34}$ En definitiva, lo que importa son los fines.

La primera conclusión que se extrae es que la intensificación de la cooperación bilateral en la lucha antiterrorista, especialmente con los países árabes y musulmanes, se perfila como una de las herramientas más útiles en la batalla contra los grupos afines a Al Qaeda que operan en España o contra intereses españoles en el extranjero. Pero esta cooperación bilateral debe incluir el intercambio de información sobre otras formas de delincuencia.

La colaboración policial marroquí nunca alcanzará el nivel de la que España mantiene con Francia, no por la información intercambiada, sino por la calidad de la misma: información antigua, soplos imprecisos de los que difícilmente se pueden extraer conclusiones válidas para operaciones policiales y confesiones inverosímiles de los detenidos. "Los marroquíes trabajan con métodos cuyos resultados no siempre son aprovechables", explica un antiguo responsable del CNI que pidió permanecer en el anonimato. "Les basta con que un islamista cante bajo tortura para que un tribunal le condene", prosigue. "Las supuestas revelaciones y en general los datos que nos comunican son, con arreglo a la legislación de un Estado de derecho, bastante inservibles", confirma un alto cargo. ${ }^{35}$

A pesar de estos problemas, la colaboración de los servicios secretos de España y Marruecos ha dado algunos frutos, como sucedió en Leganés, el 3 de abril de 2004, cuando un grupo de terroristas vinculados con el 11-M se refugiaron en un piso de este municipio madrileño, donde horas más tarde se inmolaron. La policía española intervino sus móviles pero los terroristas hablaban en árabe dialectal, por lo que los agentes españoles pidieron ayuda a la Dirección de Vigilancia del Territorio (DST), la policía política marroquí, que pronto concluyó que se iban a suicidar. Jamal Ahmidan, El Chino, a quien la policía y la justicia españolas consideran el jefe del comando que había colocado las bombas en los trenes de Atocha, anunció entonces a su madre: "Dentro de nueve minutos me iré con Dios". A las 21:03 los siete terroristas atrincherados en el piso se inmolaron. En la explosión también murió el GEO (Grupo Especial de Operaciones) Francisco Javier Torronteras. ${ }^{36}$

La cooperación hispano marroquí ha continuado desde entonces. Por ejemplo, la DST ayudó a los servicios españoles a desmantelar una célula islamista en Sant Andreu de la Barca y en Mollet del Vallés (Barcelona), integrada por marroquíes que habían intentado adquirir 400 kilos de explosivos. ${ }^{37}$

La policía española reconoce que se han desarticulado células islamistas que, una vez condenadas en un tribunal, han resultado inocentes de pertenencia a un grupo terrorista. Sin embargo valoran este trabajo porque considera que estas desarticulaciones sirven para impedir que se formen estas células. ${ }^{38}$

La llegada al Gobierno de José Luis Rodríguez Zapatero en 2004 supuso un mayor acercamiento a Marruecos. El 17 de febrero de 2005, el entonces ministro del Interior, José

\footnotetext{
${ }^{34}$ R. Blanco Patricia: "Al Qaeda camina "hacia su defunción y es imposible que la tendencia se revierta", El País, 30 de diciembre de 2008, en

http://www.elpais.com/articulo/internacional/Qaeda/camina/defuncion/imposible/tendencia/revierta/elpepuint/20 081230elpepuint_12/Tes.

${ }^{35}$ Cembrero, op. cit., pp. 142-158.

${ }^{36}$ Ibid., Ídem.

${ }^{37}$ González, Miguel: "La célula islamista detenida en Barcelona intentó comprar casi 400 kilos de explosivo", El País, 23 de diciembre de 2004.

${ }^{3838}$ Ceberio Belaza, Mónica: “Al Qaeda no tiene células operativas en España”, El País, 11 de marzo de 2011.
} 
Antonio Alonso, se reunió en Rabat con el rey Mohamed VI y con su homólogo Mustapha Sahel para reforzar la cooperación bilateral. Los dos ministros acordaron establecer una línea caliente de intercambio de información en tiempo real sobre terrorismo. Además de las lecciones aprendidas tras el 11-M sobre la vinculación entre terrorismo y otros delitos, se desprendieron importantes acuerdos en la lucha contra la delincuencia organizada, la inmigración irregular y el narcotráfico. ${ }^{39}$

El 24 de julio de 2007, España y Marruecos decidieron dar un paso más y ratificaron su propósito de impulsar la cooperación en materia de seguridad, lucha contra el terrorismo y contra la inmigración clandestina, con especial atención a la vigilancia de las fronteras, según anunció Interior. ${ }^{40}$

También hubo acuerdos en materia de Justicia. El 9 de junio de 2008, las fiscalías de España y Marruecos firmaron un acuerdo contra el terrorismo en el que se comprometían al intercambio de información sobre actividades criminales obtenidas en investigaciones o procedimientos judiciales y a la celebración de encuentros entre fiscales especializados. Días más tarde, el 24 de junio de aquel mismo año, el ministro de Justicia, Francisco Caamaño, firmó con su homólogo marroquí un nuevo convenio de asistencia judicial y otro de extradición, que sustituyeron a los acuerdos firmados en 1997. El primero permite el contacto directo entre autoridades judiciales de ambos países y el traslado de personas detenidas durante una investigación penal e incluye la excepción de los delitos de terrorismo al hablar de delitos políticos. El convenio de extradición contempla que la existencia de pena de muerte y de cadena perpetua es un motivo para denegar la extradición. ${ }^{41}$

El 23 de agosto de 2010, los ministros de Interior de España y Marruecos escenificaron el salto cualitativo que se había producido en las relaciones bilaterales entre los dos países con un nuevo compromiso de trabajar juntos en la lucha contra el terrorismo y con la firma de un acuerdo para la creación de comisarías conjuntas.

De las críticas sobre el trato condescendiente, y no de igual a igual como correspondería a un socio privilegiado, que Marruecos reprochó al Gobierno de José María Aznar tras la retirada en 2001 del embajador en $\mathrm{Madrid}^{42}$, en 2010 el entonces ministro del Interior, Alfredo Pérez Rubalcaba, presentó a Marruecos como un "aliado estratégico, creíble y responsable" que ha realizado un "importante esfuerzo en la lucha contra las redes de tráfico ilícito de inmigrantes y de trata de seres humanos", esfuerzo que ha permitido disminuir los flujos migratorios ilegales. Además, Rubalcaba destacó el éxito marroquí en la reducción de la superficie de cultivo de cannabis, en el aumento de la incautación de "grandes cantidades de droga" y en el "desmantelamiento de un importante número de redes" de narcotráfico. ${ }^{43}$

\subsection{Argelia}

Las relaciones con Argelia tampoco han sido fáciles. Sin embargo, España debe fortalecerlas por su proximidad geográfica y por su papel estratégico en la región, donde compite en liderazgo con Marruecos. Además, de Argelia procede la principal amenaza de terrorismo islamista, Al Qaeda en el Magreb Islámico (AQMI), aunque, como se ha señalado

\footnotetext{
39 “Comunicado del Ministerio del Interior", 17 de febrero de 2005.

40 "Comunicado del Ministerio del Interior", 24 de julio de 2007.

41 "Comunicado del Ministerio de Justicia", 24 de junio de 2008.

${ }^{42}$ Feliú, Laura: “España y El Magreb durante el segundo mandato del Partido Popular. Un período excepcional”, FRIDE, mayo de 2005.

43 "Comunicado del Ministerio del Interior", 23 de agosto de 2010.
} 
anteriormente, el antropólogo Jeremy Keenan atribuye la existencia de AQMI a la acción de los servicios secretos argelinos. No obstante, España está entre los objetivos de este grupo, que ha denunciado, a través de Abdelmalek Droukdel, la ocupación de Ceuta y Melilla. El secuestro de los tres cooperantes de la ONG catalana Barcelona Acció Solidària a finales de 2009 se encuadra en un objetivo de hostigamiento y chantaje a los gobiernos europeos.

En mitad de la crisis diplomática con Marruecos, el Gobierno de José María Aznar optó por una aproximación al Magreb "global y no de equilibrios", por lo que elevó las relaciones institucionales hispano-argelinas al mismo nivel que las marroquíes y firmó el 11 de octubre de 2002 un Tratado de Amistad, Buena Vecindad y Cooperación con Argelia.

España había firmado también un tratado similar con Túnez, en 1995, por lo que tan sólo restaba Argelia, ya que las relaciones económicas con Mauritania y Libia, los otros dos países que integran el Magreb, se han desarrollado siempre en un nivel muy inferior. El Ejecutivo negó entonces que el estrechamiento de lazos con Argelia estuviera relacionado con la crisis con Rabat. ${ }^{44}$ La firma del tratado coincidió, no obstante, con la aproximación entre Argel y la Unión Europea y Estados Unidos tras el 11 de septiembre.

Con la llegada al Gobierno de José Luis Rodríguez Zapatero en 2004, y en la misma línea que con la política desarrollada hacia Marruecos, se ahondó en las relaciones con Argelia. Los días 24 y 25 de febrero de 2005, se celebró una cumbre hispano-argelina al más alto nivel, -la presidieron Zapatero y el presidente argelino Abdelaziz Buteflika-, donde los dos países acordaron crear un grupo antiterrorista de cooperación judicial y policial, similar al que ya operaba en Marruecos y Francia. Además, los dos mandatarios renovaron su voluntad de "continuar y profundizar" un "partenariado estratégico" de gran contenido económico. ${ }^{45}$

Las fricciones entre Argelia y España llegaron precisamente por la estrategia antiterrorista española. O más bien por los esfuerzos españoles por liberar a los tres cooperantes de la ONG, Barcelona Acció Solidària, secuestrados el 29 de noviembre por un grupo de hombres armados. AQMI reivindicó su secuestro.

El entonces ministro de Asuntos Exteriores, Miguel Ángel Moratinos, afirmó que "el Gobierno no pagaba rescates", ante las peticiones de Argelia en este sentido, durante un nuevo encuentro entre Zapatero y Buteflika en enero de 2010 en el que firmaron acuerdos para impulsar energías renovables en el país norteafricano. ${ }^{46}$ Argel, que colaboró en la liberación de los cooperantes, rechazó públicamente el pago de rescates a AQMI porque podría servir como abono de nuevos secuestros para financiar las acciones terroristas, comprar armas, y, en definitiva, desestabilizar la región.

El Gobierno español se enfrentaba al dilema de no pagar y correr el riesgo de que los secuestradores asesinasen a los tres rehenes, o pagar y ser acusado de fomentar los ataques contra occidentales en el Magreb, y en especial en la región en la que se refugian los miembros de AQMI, entre Mauritania, Níger, Malí y Argelia. En el primer supuesto, el Ejecutivo de Zapatero se arriesgaba a un resultado similar al de Francia: atacó a una célula de

\footnotetext{
${ }^{44}$ Egurbide, Peru: "España eleva sus relaciones institucionales con Argelia al mismo nivel que las de Marruecos", El País, 7 de octubre de 2002.

45 “República Argelina Democrática y Popular", monografía del Ministerio de Asuntos Exteriores, en http://www.maec.es/SiteCollectionDocuments/Monografias/Argelia.pdf.

${ }^{46}$ Junquera, Natalia: "El Gobierno no paga rescates”, El País, 7 de enero de 2010, en

http://www.elpais.com/articulo/espana/Gobierno/paga/rescates/elpepuesp/20100107elpepunac_7/Tes
} 
Al Qaeda que presuntamente mantenía retenido al ciudadano francés Michel Germaneau, en la misma época en la que dos de los tres cooperantes españoles seguían en manos de los terroristas, y los yihadistas ejecutaron al rehén en respuesta a la represalia, según anunció la organización terrorista. ${ }^{47}$ La opinión pública no se lo hubiera perdonado y hubiera sido el blanco de los ataques de la oposición. Pero en el segundo supuesto, la opinión pública tampoco habría sido mucho más benévola. En cualquier caso, España, que logró la liberación de los tres rehenes, nunca ha reconocido el pago de un secuestro.

\subsection{Estados Unidos}

Las relaciones con Estados Unidos en los albores del siglo XXI pasaron de la plena sintonía entre el presidente español José María Aznar y su homólogo estadounidense George W. Bush, aun a riesgo de involucrar a España en un conflicto - la invasión de Irak de 2003- que carecía de los avales internacionales, al desencuentro más absoluto, con la retirada de las tropas de Irak en 2004. Mientras que en las legislaturas de Aznar, la política exterior española se caracterizó por su vocación atlantista, la de Zapatero trató de fortalecer los lazos con Iberoamérica con una política diferenciada respecto a su antecesor, y con sus vecinos del Mediterráneo, especialmente con Marruecos. Sin embargo, el acercamiento a Estados Unidos acabó siendo una prioridad del Gobierno socialista de José Luis Rodríguez Zapatero y la búsqueda de la reconciliación con Washington no dejó de estar presente en la mente del presidente.

No obstante, y a pesar de la distancia entre Bush y Zapatero, los dos países nunca dejaron de colaborar en materia de seguridad. El exministro español de Asuntos Exteriores Miguel Ángel Moratinos aseguró, en su comparecencia en el Congreso de los Diputados el 19 de junio de 2007 para ofrecer el balance de la política exterior española entre 2006 y 2007, que una vez "superado el desencuentro que supuso la retirada de nuestras tropas de Irak, mediante el respeto de puntos de vista diferentes, los contactos a nivel político y diplomático se han incrementado significativamente". Y añadió: "Mantenemos una intensa cooperación bilateral, especialmente en la lucha contra el terrorismo y en el ámbito de la defensa. En esta área hemos logrado recientemente acordar con Estados Unidos las normas de actuación en España de los agentes de los servicios de información de la Marina y de la Fuerza Aérea norteamericanas, (presencia de inteligencia militar) cuyas actividades deberán ser aprobadas y supervisadas por nuestras autoridades. Por otra parte, mantenemos fuertes consultas bilaterales en asuntos internacionales de interés común como es Afganistán, Oriente Medio, norte de África e Iberoamérica".

Aunque las diferencias entre los Ejecutivos de Aznar y Zapatero en sus relaciones con Estados Unidos son ya conocidas, por el acercamiento del primero y el distanciamiento del segundo, en gran medida se produjeron más en un plano ideológico que en el práctico, especialmente en materia de seguridad y defensa porque España no puede permitirse descuidar su relación estadounidense, aliados naturales en seguridad y defensa y, por tanto, en la lucha contra el terrorismo. Y los vuelos secretos de la CIA son una buena prueba de ello.

El escándalo de los vuelos de la CIA, el tránsito clandestino por aeropuertos europeos de sospechosos de terrorismo capturados ilegalmente y torturados en centros de detención secretos que coincidieron con el Gobierno de Aznar, explotó a Zapatero en 2005. Sin embargo, y pese al distanciamiento del entonces presidente estadounidense, George W. Bush, tanto España como la Casa Blanca trataron de minimizar su efecto en la opinión pública

\footnotetext{
${ }^{47}$ Cembrero, op. cit., pp. 142-158.
} 
española, para no deteriorar aún más las relaciones entre ambos países, según revelaron los cables de Wikileaks publicados por el diario EL PAÍS. ${ }^{48}$

\section{Conclusiones: Bilateralidad y Estado de derecho}

La articulación de una política exterior para hacer frente al terrorismo islamista se convierte en un cometido especialmente complejo cuando el punto de partida es la ausencia de una definición de terrorismo consensuada a nivel internacional, más aún cuando algunos gobernantes de países musulmanes tienden a separar movimientos de liberación de grupos terroristas. Pero estas dificultades no eximen en ningún caso al Gobierno español de desarrollar y fortalecer sus lazos internacionales para combatir la amenaza, convertida en realidad con la matanza de los trenes de Atocha.

¿Cómo luchar entonces contra el fenómeno junto con otros países cuando no se ha alcanzado un acuerdo claro sobre cuál es el fenómeno a combatir? Aunque no existe una descripción exacta, sí que se ha logrado una idea muy aproximada, especialmente a partir de la resolución 1566 del Consejo de Seguridad de Naciones Unidas.

Como fenómeno global, el terrorismo es una de las mayores preocupaciones de los organismos internacionales que abordan cuestiones de seguridad. España tiene la obligación, por su compromiso con la legalidad internacional y la defensa de los derechos humanos, de cooperar y participar en todos los procesos y foros internacionales que plantean estrategias antiterroristas. Sin embargo, los acuerdos alcanzados son más bien compromisos y carecen de carácter vinculante. Además, la presencia de países cuyas autoridades simpatizan con ciertos grupos que la Unión Europea y Estados Unidos incluyen en las listas de organizaciones terroristas desvirtúa la eficacia de estos acuerdos.

Por ello, los intentos españoles de promover iniciativas internacionales que fomenten la cooperación internacional -el caso más claro es la Alianza de Civilizaciones- constituyen un brindis al sol en materia antiterrorista. Fue uno de los puntos fuertes del programa electoral con el que José Luis Rodríguez Zapatero ganó las elecciones generales de 2004, con una clara apuesta por "reforzar y potenciar los mecanismos multilaterales desde los que se aúnan esfuerzos para afrontar retos planetarios". Pueden funcionar como campaña de marketing orientada a fortalecer la imagen de España como un país implicado en la defensa de los derechos humanos, pero parece poco probable que tengan un efecto importante en el ámbito internacional. $^{49}$

No significa, sin embargo, que España no deba contribuir a reforzar los mecanismos multilaterales para resolver problemas globales. Un ejemplo son las misiones internacionales, amparadas siempre en la legalidad, como en el caso afgano, donde la presencia de tropas bajo el mando de la OTAN es un elemento clave de la lucha contra el terrorismo yihadista, en la medida en que impiden que Al Qaeda se esconda en el país asiático para organizarse, adiestrar a sus miembros y preparar atentados terroristas.

Uno de los flancos más débiles de España es el secuestro de sus ciudadanos en el extranjero. Aunque el Ejecutivo español nunca ha reconocido haber pagado rescates, la liberación de los tres cooperantes españoles de la ONG catalana Barcelona Acció Solidària

\footnotetext{
${ }^{48}$ González, Miguel: "Los españoles no ponen reparos a los vuelos secretos", El País, 01 de diciembre de 2010.

${ }^{49}$ Programa Electoral del PSOE 2004, pp. 13-14.
} 
secuestrados por AQMI levanta sospechas. También es oscura la liberación de los marineros del buque Alakrana secuestrados el 2 de octubre de 2009 por piratas somalíes. ${ }^{50}$ Aunque en este caso los responsables no fueron terroristas, quedó patente la idea de la rentabilidad de secuestrar ciudadanos españoles, una idea que debe ser borrada a toda costa.

Sin descuidar su presencia en los organismos internacionales, España debe fortalecer las relaciones bilaterales como parte de su estrategia en la lucha antiterrorista. Lo hizo Aznar, quien por su profunda desilusión en asuntos europeos y su mal entendimiento con el expresidente francés Jacques Chirac, acabó por girar mucho más hacia el eje atlántico al considerarlo más prometedor, pera esta reorientación atlantista y su viraje incondicional hacia Estados Unidos le hizo también tratar de equilibrar sus relaciones en el Magreb entre Marruecos y Argelia. También lo hizo Zapatero, que giró de nuevo hacia Europa, desequilibró las relaciones entre Marruecos y Argelia y entorpeció las relaciones con Estados Unidos, tras la retirada del contingente español de Irak. Tanto Estados Unidos, como Europa y los Estados del Magreb son aliados en la batalla contra el terrorismo yihadista. Ninguno debe ser orillado ni menospreciado.

Sin embargo, el refuerzo de las relaciones bilaterales con cada uno de ellos exige esfuerzos diferentes. España comparte con sus aliados estadounidenses y europeos valores comunes como la democracia y el respeto y protección de las libertades civiles y sociales y de los derechos humanos. No ocurre en el mismo grado con Marruecos y Argelia. Las prácticas llevadas a cabo, por ejemplo, por los agentes marroquíes en los interrogatorios no son las propias de un Estado de derecho, por lo que la información obtenida pierde calidad. ${ }^{51} \mathrm{Y}$ esta es una de las cuestiones más problemáticas de la lucha antiterrorista porque aunque España disponga de esta información, su utilidad es muy cuestionable. Por más que se profundice y por más que se hayan alcanzado importantes avances, la cooperación policial hispanomarroquí o hispano-argelina, por ejemplo, no podrá alcanzar el nivel logrado entre España y Francia, dos Estados de derecho. Por tanto, el trabajo en el refuerzo del Estado de derecho favorece no sólo la aparición de las bases para una democracia con garantías sino también la cooperación bilateral en la lucha antiterrorista.

Más allá de la calidad de la información, la estabilidad y el desarrollo cultural, social y económico en los países del Magreb y del África subsahariana construyen una barrera a la expansión de los grupos terroristas. "Al Qaeda está en el corazón de la cultura musulmana, ofrece una patria sin fronteras, la umma, a los jóvenes sin esperanza”, sostiene el exlíder del Grupo Islámico Combatiente Libio Noman Benotman. La seguridad también pasa por el progreso.

\footnotetext{
${ }^{50}$ González, M. y Junquera, N., “Zapatero: "El 'Alakrana' navega libremente hacia aguas seguras", en El País, 17 de noviembre de 2009, en http://www.elpais.com/articulo/espana/Zapatero/Alakrana/navega/libremente/aguas/seguras/elpepuesp/20091117 elpepunac 2/Tes.

${ }^{51}$ Cembrero, op. cit., pp. 142-158.
} 